\title{
Root canal preparation: A literature review and clinical case reports of available materials and techniques
}

\author{
SADJ May 2019, Vol. 74 No. 4 p187 - p199
}

PJ van der Vyver ${ }^{1}$, M Vorster ${ }^{2}$, F Paleker ${ }^{3}$, FA de Wet ${ }^{4}$

\section{SUMMARY}

Mechanical enlargement and shaping of complex endodontic root canal systems to facilitate disinfection remain the main foci of endodontic treatment. A large variety of root canal shaping and preparation systems with different design features and advantages are available to the clinician. Although there are many studies in the literature comparing these different systems, the aim of this paper is to provide the clinician with an overview of some of the available systems as well as their clinical applications.

\section{INTRODUCTION}

Shaping and enlargement of root canal systems to facilitate irrigation, disinfection and proper obturation are the most important aspects in endodontic treatment. ${ }^{1}$

Maintaining the original canal anatomy and preservation of dentine thickness of a root canal system is critical to the successful shaping of a root canal. Procedural errors like instrument fractures, ledge formation, canal zipping,

\section{Author affiliations:}

1. Peet van der Vyver: BChD, PG Dip Dent (Endo), PG Dip Dent (Aesthet Dent), MSc, PhD (Pret), Department of Odontology, School of Dentistry, University of Pretoria, Pretoria, South Africa and Private Practice, Sandton, South Africa. ORCID Number 000-0003-1951-6042

2. Martin Vorster: BChD (Pret), PG Dip Dent (Endo), MSc (Pret), Department of Odontology, School of Dentistry, University of Pretoria, Pretoria, South Africa. ORCID Number 0000-0003-4470-1530

3. Farzana Paleker: $B C h D$ (Stell), Dip Odont (Endo), MSc (Pret), Department of Odontology, School of Dentistry, University of Pretoria, Pretoria, South Africa.

ORCID Number 0000-0002-5446-309x

4. Francois A de Wet: $B C h D, M S c, D S c$ (Pret), Department of Odontology, School of Dentistry, University of Pretoria, Pretoria, South Africa.

ORCID Number 0000-0003-4279-3902

Corresponding author: PJ van der Vyver

Tel: +27 (0)117811020 Email: peetv@iafrica.com

Author contributions:

1. Peet van der Vyver: Responsible for some of the scientific writing and planning of the article. Provided most of the clinical cases reported in the article.

2. Martin Vorster: Responsible for some of the scientific writing, contributed to the writing of the abstract, literature review as well as concluding remarks and was also involved in the editing and proofreading of the article as well as editing and verifying of references.

3. Farzana Paleker: Responsible for some of the scientific writing, final layout of the article and collecting cases that were not provided by Prof $P$ vd Vyver.

4. Francois A de Wet: Responsible for some of the scientific writing and for proofreading of the article. strip perforations, apical perforations, elbow formations and apical blockage can possibly lead to endodontic failure as a result of incomplete debridement. ${ }^{2}$ Most of these errors can be contributed to the stiffness of stainless steel instruments. ${ }^{3}$

The introduction of nickel titanium (NiTi) rotary instruments with a decreased modulus of elasticity, revolutionised endodontics. Recent developments in endodontic instrumentation can be characterised by more flexible alloys with an increase in fatigue resistance, altered shaping motion (reciprocation in addition to rotation action) and a reduction in the number of files used for canal enlargement and shaping. ${ }^{4}$ Improved design of file systems in order to clean a greater section of the canal without the need for coronal flaring has also become one of the key features of recently developed endodontic systems. ${ }^{5}$

Mechanical preparation goes hand in hand with chemical disinfection of the root canal system and should be studied concurrently. In this paper the authors will however only focus on the mechanical aspects of a few different canal shaping systems, their advantages, design features and clinical applications.

\subsection{BioRaCe (FKG Dentaire)}

BioRaCe (FKG Dentaire, La Chaux-de-Fonds, Switzerland) (Figure 1) is a rotary NiTi shaping system consisting of instruments that are manufactured using a conventional austenite NiTi electro-polishing surface treatment, have a non-cutting safety tip, and a triangular cross section with alternating cutting edges. ${ }^{6}$ The basic set has six instruments: BR0 (25/08), BR1 (15/05), BR2 (25/04), BR3 (25/06), BR4 (35/04) and BR5 (40/04). According to the manufacturer, the varying diameters and tapers of this sequence reduce the contact area of each instrument with the canals walls, which minimises stress and provides the ability to safely reach the working length.

A recent study compared the shaping ability of two rotary file systems; BioRaCe and ProTaper NEXT (Dentsply Sirona, Baillagues, Switzerland) (PTN) during the preparation of curved root canals and in extracted teeth with the use of micro-computed tomographic imaging. ${ }^{7}$ This study evaluated procedural errors in curved root canals and found that both instrumentation systems caused negligible procedural errors with minimal apical transportation. 
Pasqualini et al. (2015) evaluated the shaping properties of two glide path-shaping NiTi rotary systems: ProGlider/ProTaper NEXT (Dentsply Sirona) (PG/PTN) and ScoutRaCe/Bio-RaCe (FKG Dentaire) (SR/BR). ${ }^{7}$

Specimens were scanned for matching volumes; surface areas and post-treatment analyses with the use of micro-CT. These researchers concluded that both SR/BR and PG/PTN shaping systems provided root canal preparation without significant shaping errors in maxillary first molar curved canals. The PG/PTN system, however, resulted in a more centered and less invasive preparation.

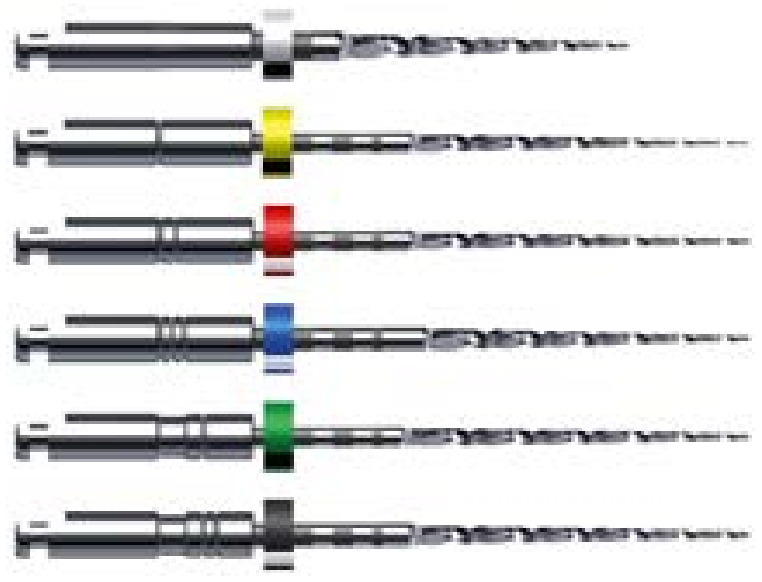

Figure 1. BioRaCe (FKG Dentaire) instruments from top to bottom: BR0 (white), BR1 (yellow), BR2 (red), BR3 (blue), BR4 (green), and BR5 (black).

\section{Case report}

The patient, a 43 year old female presented with irreversible pulpitis on a recently crowned mandibular right first molar (Figure 2a). After access cavity preparation, three root canal systems were located (mesiobuccal, mesiolingual and distal) and length determination was confirmed radiographically (Figure $2 \mathrm{~b}$ ).

Glide path preparation was done with ScoutRace files (ISO sizes 10,15 and 20) followed by root canal preparation with the BioRace file system. The two mesial root canal systems were prepared with five instruments ((BR0 (25/08), BR1 (15/05), BR2 (25/04), BR3 (25/06),
BR4 (35/04)) and the distal canal with six instruments ((BR0 (25/08), BR1 (15/05), BR2 (25/04), BR3 (25/06), BR4 (35/04) and BR5 (40/04)). Figure 2c shows the final result after root canal obturation.

\subsection{OneShape (Micro-Mega)}

OneShape (Micro-Mega, Besançon, France) (Figure 3) is a single-file NiTi rotary shaping system made of a conventional austenite 55-NiTi alloy. The instrument has a tip size of 25 , a constant taper of $6 \%$, and is characterised by different cross-sectional designs over the entire length of the file. ${ }^{9}$ This single-file instrumentation system is used in a full clockwise rotation. The cross section of the tip region has three cutting edges. The cross section of the middle region progressively changes from a three-cutting-edge design to two cutting edges, and the cross section of the shank is an S-shaped cross section with two cutting edges. The asymmetric cross section geometry of the file generates travelling waves of motion along the active part of the file. ${ }^{8}$

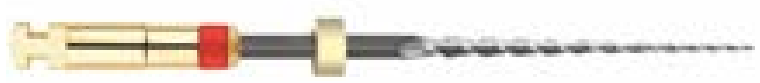

Figure 3. OneShape single file NiTi rotary file.

A 2015 study compared the amount of apically extruded bacteria following the use of OneShape-, PTN- and Twisted File (TF) (TF; SybronEndo, Orange, CA) systems. ${ }^{10}$ The study concluded that all instrumentation systems extruded bacteria beyond the foramen but that the OneShape system extruded fewer bacteria compared with the TF- and PTN systems.

The results of the study by Bürklein, Benten and Schäfer showed that OneShape decreased the preparation time by $59 \%$ compared with Mtwo (VDW, Munich, Germany), a full-sequence rotary $\mathrm{NiTi}$ system. ${ }^{9}$ A concern raised in this paper and in earlier studies was the associated decrease in irrigation time and subsequent chemical debridement of the root canal system. As a result, these authors recommended increased volumes of irrigation solutions in addition to irrigant activation for improved chemical dissolution of residual debris and disinfection of the root canal system.
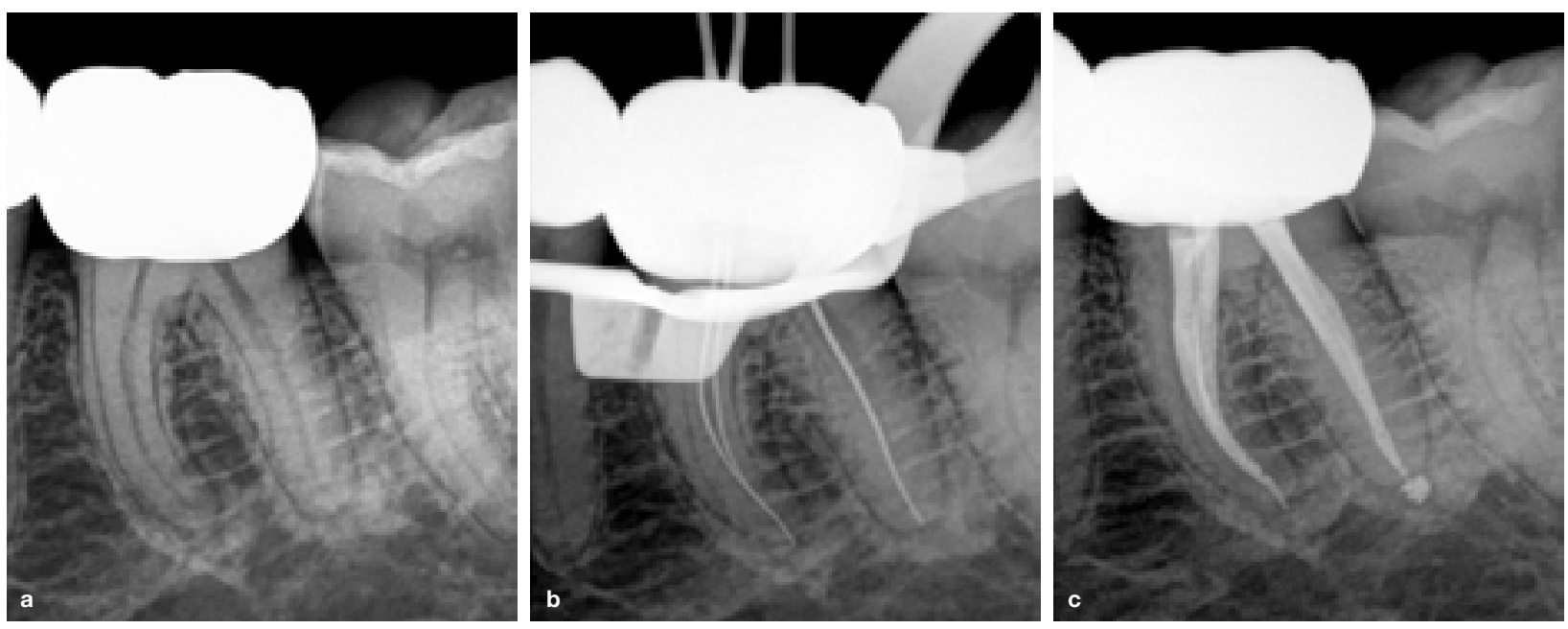

Figure 2. (a) Preoperative periapical radiograph;

(b) Working length confirmed radiographically;

(c) Postoperative result after obturation. 
This study also examined canal straightening, as well as preparation time. The results for all the instruments were comparable with those of other investigations carried out under similar experimental conditions. ${ }^{11,12}$ The mean straightening value for OneShape was $1.74^{\circ}$ and for Reciproc - a single-file reciprocating system - was $1.35^{\circ}$.

A study evaluating canal straightening and apical transportation between OneShape-, WaveOne- and Reciproc instruments showed significantly less canal straightening and apical transportation in the WaveOne and Reciproc groups. These researchers attributed the results to the flexibility of the instruments in these two groups, which stems from its M-Wire construction. ${ }^{13}$ Pereira et al. have shown that the physical and mechanical properties of $\mathrm{M}$-Wire renders root canal instruments more flexible and more fatigue resistant than those made from conventional austenitic NiTi, like OneShape. ${ }^{14}$

According to these researchers, another feature that contributed to these results was the use of WaveOne and Reciproc in a reciprocating motion as opposed to the continuous rotation of OneShape. Several studies have claimed that this working motion is associated with well-centered preparations and reduced procedural errors. ${ }^{15,16}$ Furthermore, this reciprocating motion extends the lifespan of instruments in comparison with continuous rotation. ${ }^{17,18}$ OneShape, however, prepared the root canals significantly faster than did Reciproc and WaveOne. All the file systems considered in the study by Peraira et al. successfully maintained the original curvature of severely curved canals in extracted teeth. These results are in accord with those found in other studies. ${ }^{8,12,19,20}$

\section{Case report}

The patient, a 32 year old male presented with a history of an emergency root canal treatment on his maxillary right first premolar (Figure 4a). After glide path preparation with a One $G$ instrument (Micro-Mega, Besançon, France) both root canal systems were prepared with the OneShape (25/06) instrument. Figures $4 \mathrm{~b}$ illustrates the cone-fit radiograph to confirm the fit of two size 25/06 gutta-percha points. The final result after root canal obturation is shown in Figure 4c.

\subsection{ProTaper Gold (Dentsply Sirona)}

ProTaper Gold instruments (PTG) (Dentsply Sirona) (Figure 5) are newly introduced endodontic instruments with the same geometries as ProTaper Universal instruments (PTU) (Dentsply Sirona). The manufacturer claims that these instruments present enhanced mechanical properties because of their innovative metallurgy, which exhibits two-stage specific transformation behaviour and high Af temperatures. ${ }^{21}$ Like the PTU and PTG instruments, each demonstrates a convex triangular cross section and has a continuously changing helical angle.

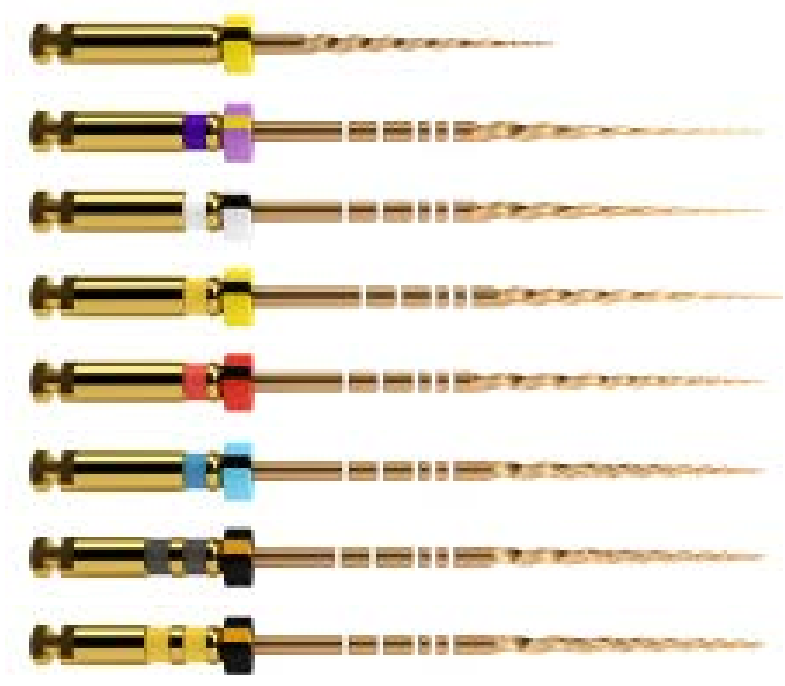

Figure 5. ProTaper Gold instruments (Dentsply Sirona):

SX (top), S1 (purple), S2 (white), F1 (single striped yellow), F2 (red), F3 (blue), F4 (black), and F5 (bottom).

Each instrument falls into one of two categories: shaping instruments (SX, S1, S2) and finishing files (F1, F2, F3, F4, F5). Although shaping instruments demonstrate a progressively tapered design, finishing instruments have fixed tapers between D1 and D3, and their tapers decrease progressively from $\mathrm{D} 4$ to $\mathrm{D} 14 .{ }^{22}$ The study by Hieawy et al. (2015) examined phase transformation behaviour and resistance to bending and cyclic fatigue of PTG and PTU. ProTaper Gold files were found to be significantly more flexible and resistant to fatigue than PTU files. ${ }^{21}$
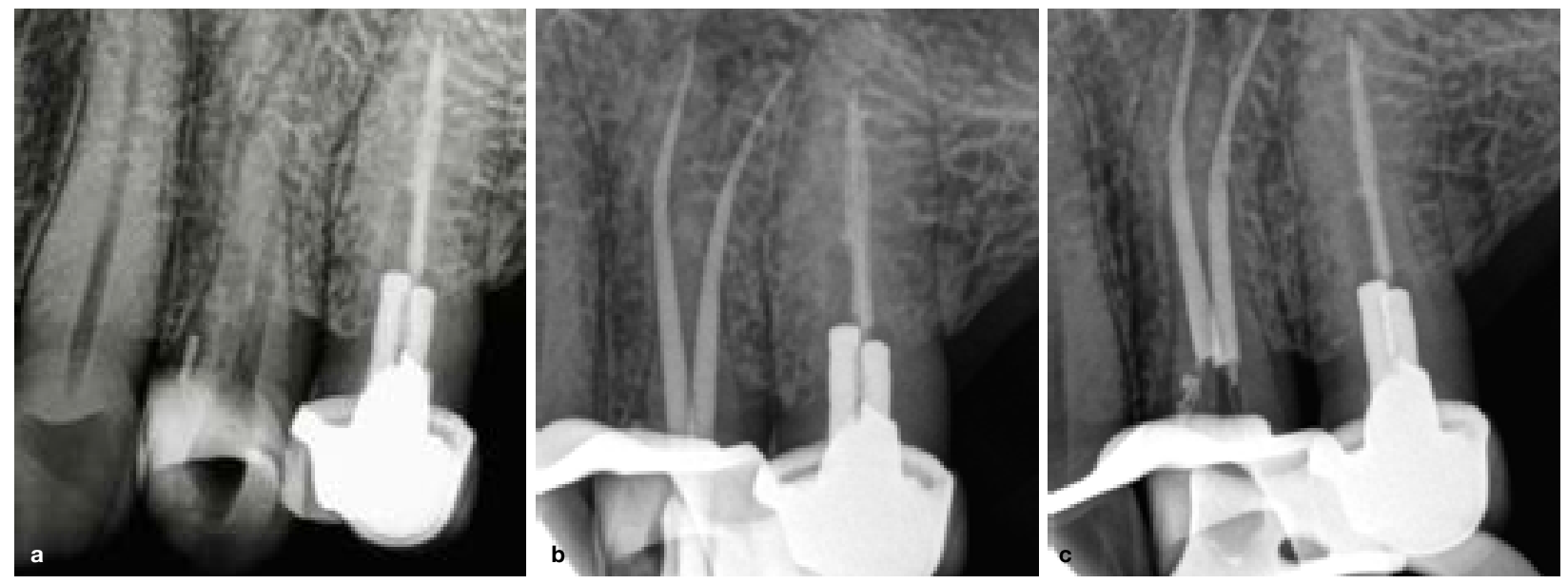

Figure 4. (a) Preoperative periapical radiograph;

(b) Periapical radiograph confirming the fit of the gutta-percha points;

(c) Postoperative result after obturation. 
The fatigue life of size S1 and S2 was significantly longer than that of sizes F1 to F3 files. Apart from demonstrating two-stage transformation behaviour, the study found that Af temperature of PTG instruments $\left(50.1^{\circ} \mathrm{C} \pm 1.7^{\circ} \mathrm{C}\right)$ was higher than that of PTU instruments $\left(21.2^{\circ} \mathrm{C} \pm 1.9^{\circ} \mathrm{C}\right)$. A recent study evaluated the cyclic fatigue and torsional resistance of Hyflex EDM files (Coltene/Whaledent, Altstätten, Switzerland), PTG instruments and PTU instruments through the use of a stainless steel block with $1.5 \mathrm{~mm}$ diameter and $3 \mathrm{~mm}$ radius of a $60^{\circ}$ angle of curvature..$^{23}$

In this study, Hyflex EDM files demonstrated significantly higher resistance to cyclic fatigue which could be explained by the controlled memory effect of the NiTi alloy (CM-Wire) and Electric Discharge Machining (EDM) process during construction, which allows wellcontrolled-and non-contact shaping of the files and could improve their mechanical properties.

ProTaper Universal instruments presented lower cyclic fatigue and torsional resistance than did PTG instruments in spite of their similar design. These results were in accord with those presented by Elnaghy and Elsaka who also attributed the results to the metallurgy of PTG. ${ }^{24}$

A separate study comparing the flexibility and cyclic fatigue resistance of PTG and PTU showed that PTG files were significantly more flexible and resistant to fatigue than were PTU files. ProTaper Gold instruments and PTU exhibited dissimilar phase transformation behaviour, which may be attributed to the special heat treatment history of PTG instruments. These researchers concluded that PTG might be more suited for preparing canals with more abrupt curvatures.

A study examining canal transportation in simulated curved canals prepared with PTU and PTG showed that these two systems produced similar canal transportation in the straight part of the canal. ${ }^{25}$ In the curved part, however, Silva et al. found that the PTG system produced overall less canal transportation when compared with the PTU system. This finding contrasts with a study that showed PTG and PTU as having similar root canal shaping abilities in the preparation of mesial canals of mandibular first molars. ${ }^{24}$ It is important to note that the former study examined colour stereo microscopic images after shaping resin blocks while the latter used CBCT images.

\section{Case report}

The patient, a 41 year old female presented with a nonvital mandibular left first molar (Figure 6a). After access cavity preparation, four root canal systems were detected (mesiobuccal, mesiolingual, distobuccal and distolingual) and length determinations were confirmed radiographically (Figure 6b). Glide path preparation was done with a ProGlider (Dentsply Sirona).

After glide path preparation another distal canal (middistal) was detected. Root canal preparation of the five root canal systems were done with the S1, S2, F1 and F2 ProTaper Gold instruments.

Figure 6c depicts the final result after root canal obturation with Protaper Gold F2 Gutta Percha Points (Dentsply Sirona) and Pulp Canal Sealer (Kerr, Bioggio, Switzerland), using System B (Kerr) and Obtura II (Obtura Spartan) obturation units. Note that the mid-distal canal joins in the apical third with the distobuccal root canal system to end in one apical foramen.

\subsection{ProTaper NEXT (Denstply Sirona)}

The ProTaper NEXT (Denstply Sirona) rotary shaping system is reported to deliver the same predictable results as its predecessor PTU (Denstply Sirona), but reportedly with greater efficiency and with fewer files.

There are five instruments in the system but, according to the manufacturer, most canals can be prepared with the use of the first two only. The system comprises $X 1$ (17.04), X2 (25.06), X3 (30.07), X4 (40.06), and X5 (50.06) (Figure 7 ), which are all characterised by a rotational phenomenon known as "precession" or "swagger".

This innovative off-centered rectangular cross section is claimed to give the files a "snake-like" swaggering move-
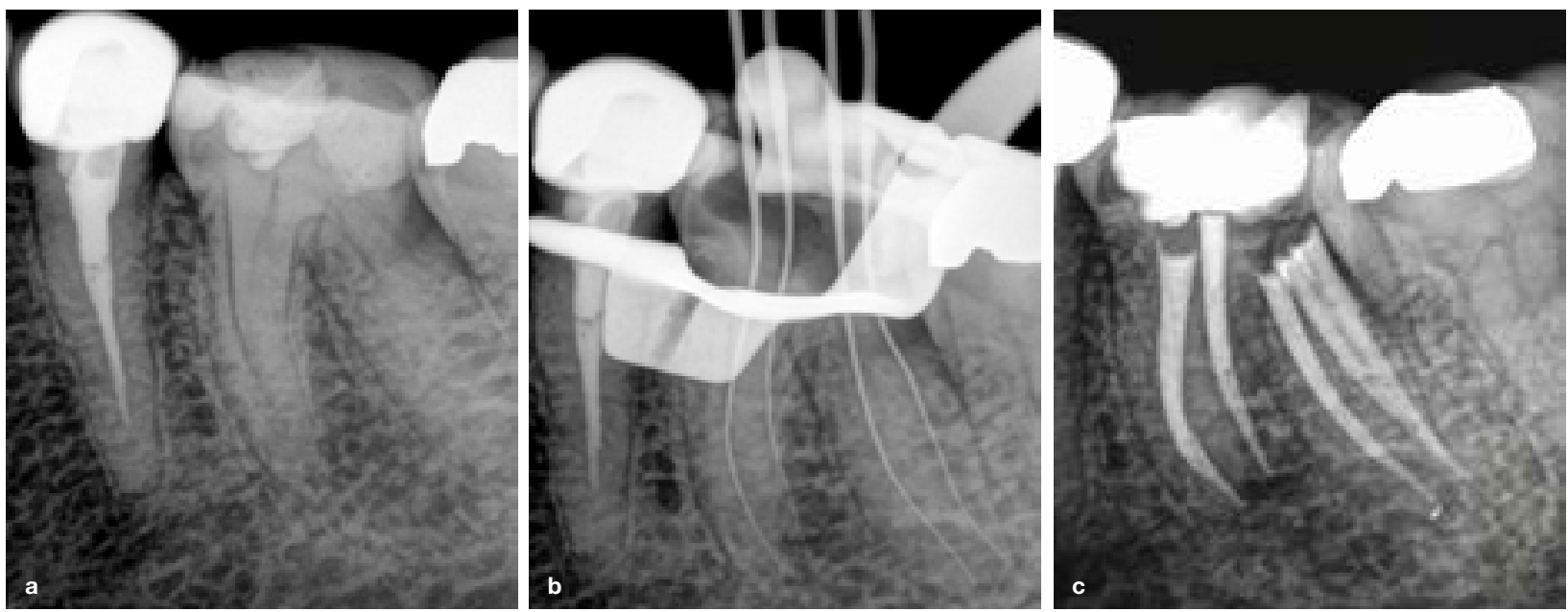

Figure 6. (a) Preoperative periapical radiograph;

(b) Working length of two mesial and two distal root canal systems confirmed radiographically;

(c) Postoperative result after obturation. Note the three distal root canals, with the mid-distal canal joining with the distobuccal root canal system in the apical third. 
ment as they advance into the root canal $^{26}$ (Figure 8a and b). ProTaper NEXT features a bilateral symmetrical rectangular cross section with an offset from the central axis of rotation, except in the last $3 \mathrm{~mm}$ of the instrument (D0-D3). The exception is ProTaper X1, which has a square cross section in the last $3 \mathrm{~mm}$ to give the instruments a little more core strength in the narrow apical part.

The shorter handle of PTN also allows for improved accessibility to teeth and the file's M-Wire NiTi construction increases flexibility and makes it almost 400\% more resistant to cyclic fatigue, decreasing the potential for broken instruments. ${ }^{27}$

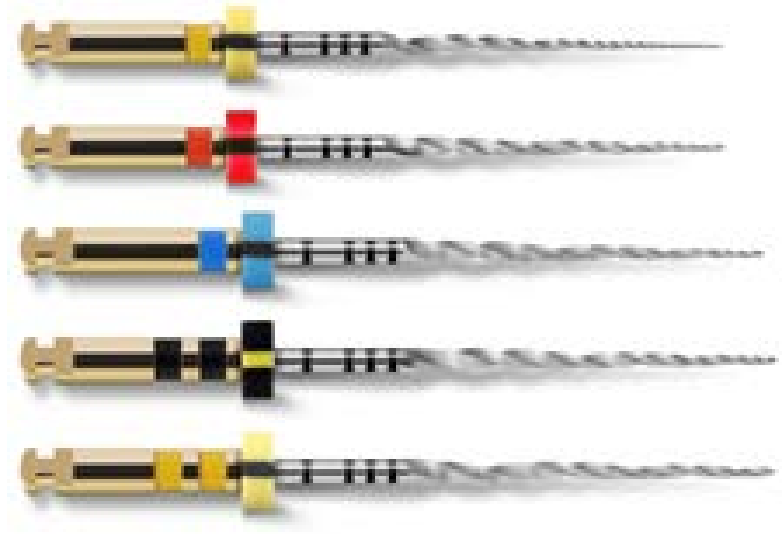

Figure 7. ProTaper NEXT files (Dentsply Sirona): X1 (top), X2 (red), X3 (blue), X4 (black) and X5 (bottom).
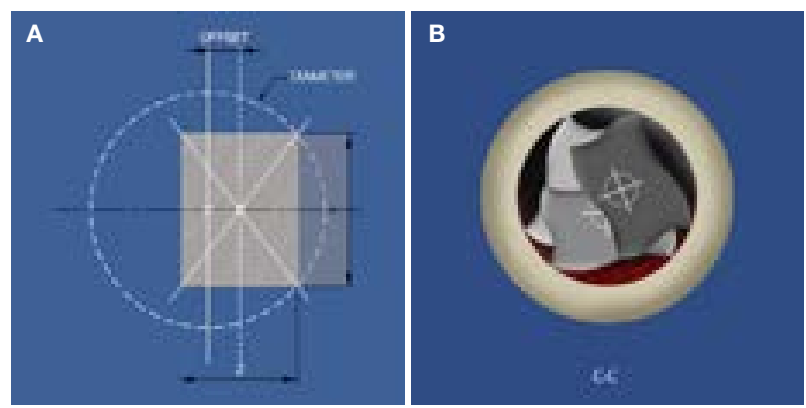

Figure 8. Schematic representation of (a) an off-set rectangular file demonstrating the adjustability of the distance of the offset from the centra axis; (b) rectangular offset cross section of ProTaper NEXT showing two points of contact with the dentine wall as the file rotates (Courtesy of Dr. M Scianamblo, San Rafael, California).
According to van der Vyver and Scianamblo the benefits of the PTN design include: ${ }^{28}$

1. Further reduction in the engagement between the instrument and the dentine walls, which contributes to a reduction in taper lock, screw-in effect, and stress on the file.

2. Removal of debris in a coronal direction because the off-centre cross section allows for more space around the flutes of the instrument, leading to improved cutting efficiency through continuous contact of the blades with the surrounding dentine walls.

3. The swaggering motion of the instrument initiating activation of the irrigation solution during canal preparation and improving debris removal.

4. Reduced risk of fracture through less stress on the file and more efficient debris removal.

5. The ability of each instrument to perform a larger envelope of motion (larger canal preparation size) compared with a similarly sized instrument with a symmetrical mass and axis of rotation. This allows the clinician to use fewer instruments to prepare a root canal to adequate shape and taper to allow for optimal irrigation and obturation.

6. A smooth transition between instruments because of a design that ensures sequential and exponential expansion of performance.

A study of curved canals by Pasqualini et al. that compared PTN to the BioRaCe system (BR) (FKG, Dentaire) demonstrated that PTN resulted in a more centered and less invasive preparation than that obtained with the BR system. ${ }^{7}$

That study showed no significant differences in postinstrumentation volumes and surface areas between the two groups. However, at a level $1 \mathrm{~mm}$ from the canal apex and at the point of maximum curvature, lower canal transportation scores were recorded for PTN used after glide path enlargement than for the BR instrument used after glide path enlargement with ScoutRaCe (FKG Dentaire).
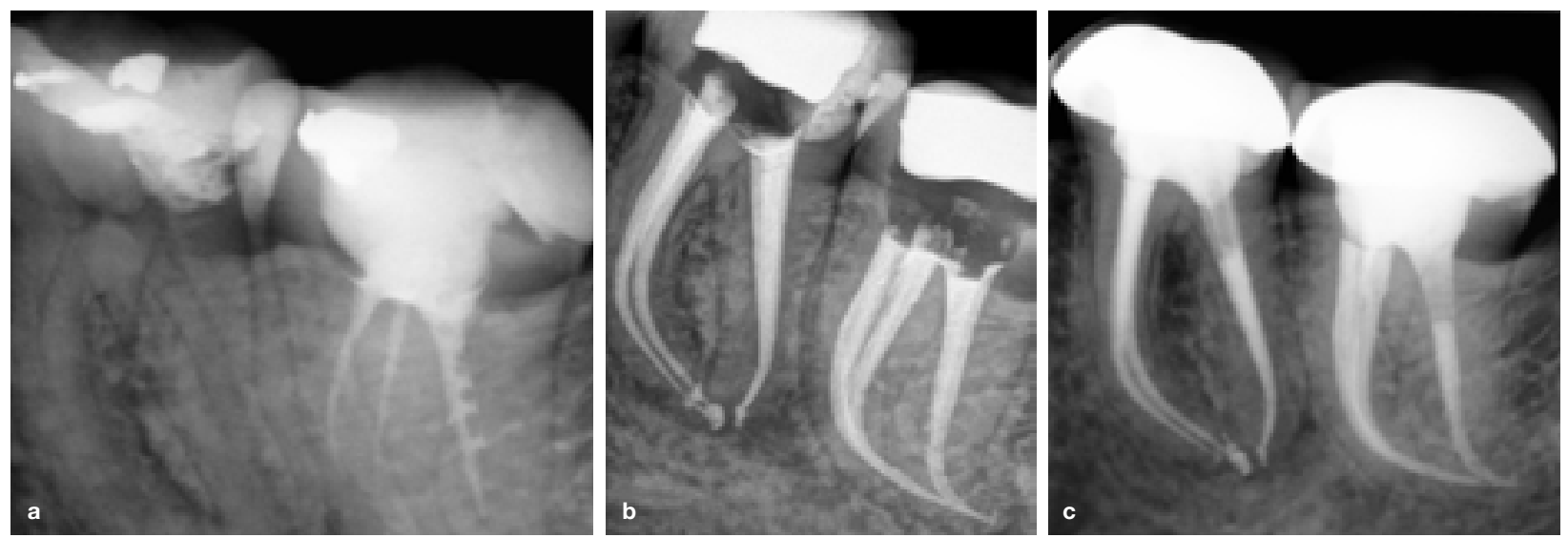

Figure 9. (a) Preoperative periapical radiograph;

(b) Immediate postoperative result after the root canal systems were obturated with six size 25 Thermafil Obturators:

(c) Postoperative result four years after the teeth were restored. 
Centrifugal increase in canal diameters between the two groups was similar but PG/PTN demonstrated a more conservative increase of canal areas and a reduction of the inner dentinal wall thickness at the point of maximum curvature. The same study also analysed the final canal taper after shaping with PTN X2 in 3D. Results showed a homogeneous increase in canal taper, ranging from $6 \%$ to $7 \%$, which was consistent with the declared taper of the instrument profile.

A study by Da Silva Limoeiro et al. demonstrated the inability of NiTi systems to completely shape root canal walls. The authors showed that following instrumentation with BR, $11.42 \%$ of the surfaces were untouched, while $15.46 \%$ of the walls remained unprepared after the use of PTN. ${ }^{29}$ These values are in line with those reported by Busquim et al. in which files left $9 \%$ to $16 \%$ of the walls untouched ${ }^{30}$ and with those reported by Gagliardi et al. who found a mean range of $6 \%$ to $13 \%$ of untouched areas. ${ }^{27}$ The Gagliardi et al. (2015) study evaluated the shaping characteristics of PTG, PTN, and PTU in curved canals, and showed that the first and last of these systems produced significantly less transportation than PTN and that PTG maintained more dentine than PTU. PTN, however, displayed less canal wall contact than either PTG or PTU. ${ }^{29}$

A study used micro-computed tomography to evaluate the frequency of dentinal micro-cracks after root canal preparation with PTN- and TF Adaptive systems (Kerr). ${ }^{31}$ Results showed that root canal preparation with the two systems did not induce the formation of new dentinal micro-cracks. ${ }^{31}$

\section{Case report}

The patient, a 29 year old female presented with a non-vital mandibular left first molar and a poorly root canal treated second molar (Figure 9a). After removal of the previously placed gutta-percha in the second molar all the root canal systems in both teeth were negotiated to patency.
Glide path preparation was done with PathFiles (Dentsply Sirona) and root canal preparation was done with the X1 and X2 ProTaper NEXT instruments. Obturation of the six root canal systems was effected with size 25 Thermafil Obturators (Dentsply Sirona) (Figure 9b). Figure 9c shows the result at a four year follow up visit.

\subsection{TRUShape 3D Conforming Files (Dentsply Sirona)}

TRUShape 3D Conforming Files (TRS) (Dentsply Tulsa Dental Specialties, Tulsa, OK, USA) (Figure 10) were launched in 2015 in four available sizes $(20,25,30$, 40), each with a variable regressive $6 \%$ taper to a maximum flute diameter of $0.80 \mathrm{~mm}$.

All instruments have the same symmetric triangular cross section and exhibit an S-curve shape, resulting in a variable overall taper of the instrument. The cutting part of these instruments is made of heat-treated NiTi alloy with proprietary processing. The heat treatment is applied after flutes are ground into blanks from commercially available nickel titanium to shape-set a file into characteristic bends. ${ }^{32}$

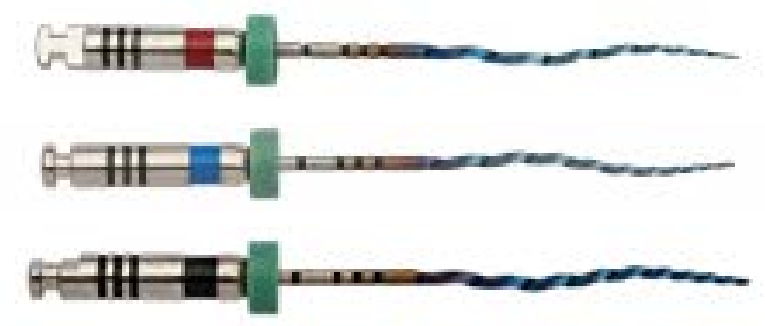

Figure 10. TRUShape 3D Conforming Files (26/06, 35/06 and 40/06) (Dentsply Tulsa Dental Specialties)

The unique S-shape of the TRS files creates an innovative envelope of motion within the canal that conforms to unconstrained spaces while respecting constrained spaces. This shape allows the files to adapt to areas of the canal greater than the nominal size of the instrument. TRUShape 3D Conforming Files are claimed to preserve more dentinal structure when they are used to prepare the entire root canal. ${ }^{33,34}$
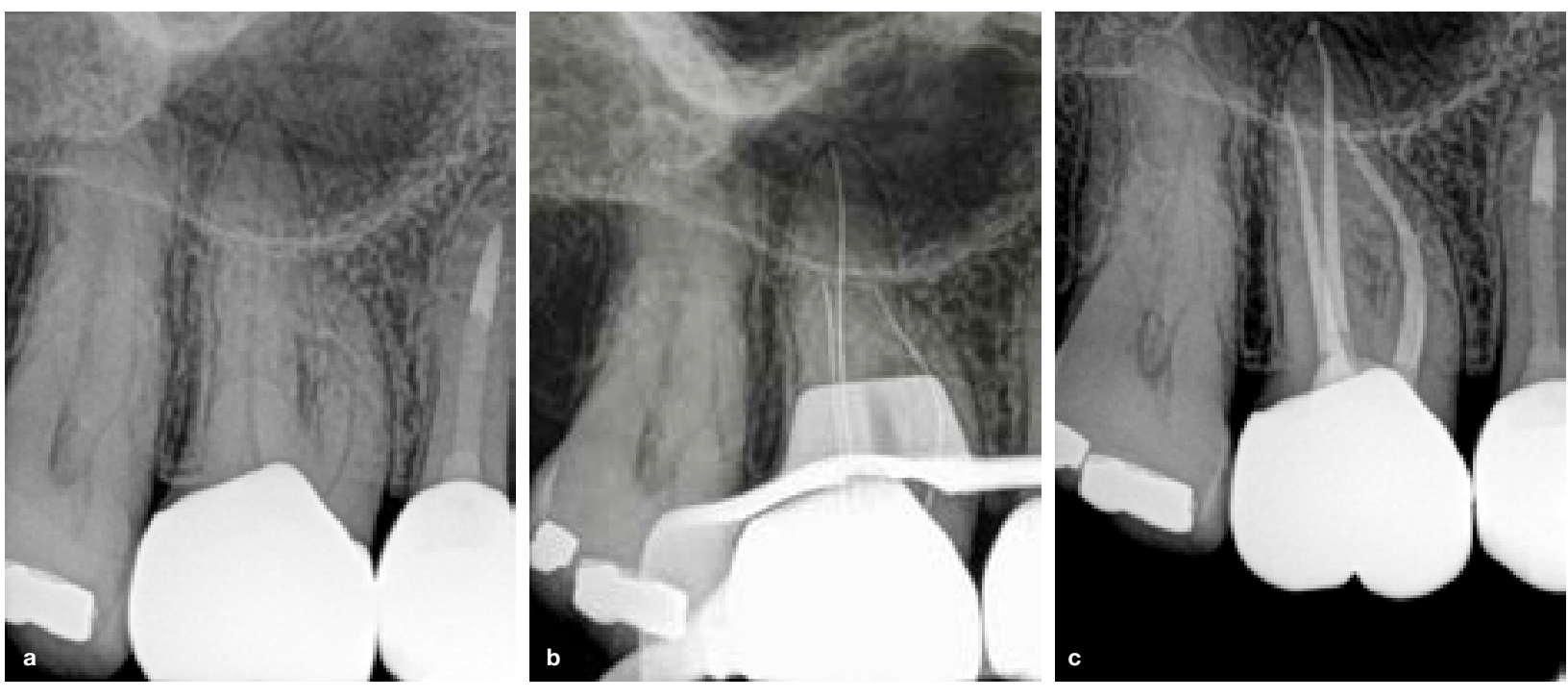

Figure 11. (a) Preoperative periapical radiograph;

(b) Working length confirmed radiographically;

(c) Postoperative result after obturation 
TRUShape 3D Conforming Files are reported as allowing for a predictable apical shape while producing up to $32 \%$ less apical transportation than conventional ISO prepared canals. The TRS instruments are also reported to reduce bacteria loads from root canal walls in the absence of antimicrobial irrigant more than do Twisted Files (SybronEndo). ${ }^{35}$

\section{Case report}

The patient, a 52 year old female patient presented with a non-vital maxillary right first molar (Figure 11a). After access cavity preparation the working length of the three located root canal systems (mesiobuccal, distobuccal and palatal) were confirmed radiographically (Figure 11b). Glide path preparation of the three located root canal systems were done with a ProGlider instrument and root canal preparation was done with the 25/06 TRUShape 3D Conforming File. Figure 11c demonstrates the final result after root canal obturation.

\section{Reciprocating root canal shaping systems}

Nickel titanium instruments used in a reciprocating motion were recently introduced for endodontic shaping. Reciprocating $\mathrm{NiTi}$ files differ from NiTi files that use continuous rotation by working in a similar but reverse "balanced force" action, using a pre-programmed motor to move the files in a back and forth "reciprocal motion". 36

A significant limitation of the $\mathrm{NiTi}$ instruments used in rotation has been the fracture rate of these files, which has been attributed to the effects of the continuous rotation. ${ }^{37,38}$ There are claims that reciprocating endodontic instruments are more resistant to instrument separation, allow for easier treatment and, ultimately, will shorten the learning curve for NiTi file systems. ${ }^{39}$

The reciprocating working motion consists of a cutting direction that is counter-clockwise (CCW) and a reverse direction that is clockwise $(\mathrm{CW})$. The fact that the angle of the CCW cutting direction is greater than the angle of the reverse direction is alleged to ensure that the instrument continuously progresses towards the terminus of the root canal. ${ }^{9}$

The resistance to separation of reciprocating endodontic instruments can be explained by the endurance limit, defined as the level of torsional stress or strain at which a file can be subjected to virtual infinite cycles without failure, where a cycle is regarded as a loading and releasing stress or strain. ${ }^{40}$ This value will be a specific deflection angle characteristic of each instrument and it will depend on the size and design features. ${ }^{40}$

Virtually each time that a file is cutting dentine in rotation and is constricted inside the canal, a certain degree of torsional deformation develops on its axis. If this deformation is maintained under the limits of the plastic deformation, there will be no structural changes. However, if this repeated cyclic axial deformation is accrued and exceeds the endurance limit, the metal will fracture because of torsional fatigue. This mechanism of stress is added to the flexural fatigue that is developed within a curved root canal. ${ }^{41}$
The idea of limiting the angle of rotation in the cutting motion under the endurance limit of the instruments led to the development of the reciprocating movement. The aim was to create a motion with a rotary effect in which the angle of rotation in the cutting motion is higher than the angle of rotation in the opposite noncutting direction. This determines the final rotation of the instrument that will perform a complete rotation for a certain number of reciprocating cycles. ${ }^{39}$

Stainless steel files have been used in a similar motion during glide path enlargement. Studies have demonstrated that $\mathrm{NiTi}$ reciprocating instruments decrease preparation time, increase cyclic fatigue life, and have a shaping ability similar to that of systems that use continuous rotation. ${ }^{42-44}$ Incidences of deformation and fracture of reciprocating instruments are fewer than those reported for rotary instruments. ${ }^{45,46}$ Another reported advantage of using reciprocating endodontic systems is that in contrast to conventional rotary systems that utilise a series of instruments for shaping, reciprocating systems such as WaveOne (Dentsply Sirona) and Reciproc (VDW), are able in some cases to shape canals with the use of one instrument only. ${ }^{47}$ Significantly fewer incidences of instrument separation and deformations of reciprocating files have been reported. ${ }^{45,46}$

Studies comparing the fracture risk of conventional rotating files and reciprocating instruments showed a significantly higher number of fractures in the rotating file group. ${ }^{15,48}$ Further reports show that file deformation and life span are not influenced by operator experience or the establishment of a mechanical glide path. ${ }^{49-51}$ Wan et al. claim that reciprocating files undergo decreased stress and should therefore have a greater fatigue resistance because these files travel shorter circumferential distances than do rotary files. ${ }^{52}$ Various studies have concluded that the reciprocating motion extends the life span of NiTi endodontic files. ${ }^{53-55}$

\subsection{Properties of reciprocating root canal shaping systems}

\subsubsection{Cyclic fatigue and bending resistance}

The amplitude of reciprocation has been shown to influence the cyclic fatigue life of reciprocating files. Increased angles of reciprocation with subsequent increases in the angle of progression for each reciprocation cycle reportedly reduce the resistance to cyclic fatigue. ${ }^{56,57}$

A study by Shin et al. reported that the fatigue life is reduced when the reciprocating amplitude increases in stationary reciprocation (i.e. reciprocation remains constant and the instrument does not progress down the canal) but may be increased by $50 \%$ to $355 \%$ over the fatigue life associated with conventional rotating files. ${ }^{58}$

The results for progressive reciprocating files are even higher, for a fatigue life enhancement of up to $990 \%$ beyond that of conventional rotating files may be achieved. During progressive reciprocating motion, the most critically strained locations move forward to new sites as the file advances, distributing fatigue damage to various points on the circumference of the instrument. 


\subsubsection{Cutting efficiency}

Studies examining the cutting efficiency of Reciproc, Twisted File (TF) Adaptive (SybronEndo, Orange, CA) in both reciprocating files and conventional rotating modes showed no significant difference in the cutting ability between the two types of movement. ${ }^{59,60}$ There are,however, only a few studies investigating the cutting efficiency of the new reciprocating files. Plotion et al. and Tocci et al. revealed that Reciproc and TF Adaptive exhibited significantly higher cutting efficiency than WaveOne. ${ }^{61,62}$

Another study by Gambarini et al. showed that the cutting ability was not reduced by prolonged clinical use. ${ }^{59}$ A combination of the two movements has proved successful. Conventional rotating files used during glide path enlargement and shaping with reciprocating files have produced centered preparations. Berutti et al. found that endodontic preparation with the Primary WaveOne file following glide path enlargement with the PathFile system produced a preparation that was more centered. ${ }^{42}$

\subsubsection{Other Reported Advantages}

Two studies compared the extrusion of debris during retreatment procedures using either rotary files or reciprocating files, the results showing that reciprocating files are associated with reduced debris extrusion. . $3,64^{6}$ Reciprocating files are effective in removing the root canal filling material in less time compared with rotary files. These files also seem to cause fewer or an equivalent rate of dentine micro-cracks compared with rotary full-sequence systems. ${ }^{65}$ A study by Alattar, Nehme and Diemer demonstrated that increasing the number of brushing strokes creates increased dentinal cutting in the direction of those strokes. ${ }^{6} 6$

\subsection{WaveOne (Dentsply Sirona)}

In 2011, the WaveOne NiTi files system (Dentsply Sirona) (Figure 12) was launched as a single-use single-file system to shape the root canal in a reciprocating motion. The system is constructed of M-Wire and is made up of three files. The WaveOne Primary (25/08) and WaveOne
Large (40/08) files have fixed tapers of $8 \%$ from D1-D3, whereas from D4-D16, the instruments demonstrate a progressively decreasing percentage tapered design. ${ }^{67}$ The WaveOne Primary file is used to prepare the majority of root canals with a secured glide path preparation. The WaveOne Large file is mainly indicated for larger diameter and relatively straight root canal systems. ${ }^{36}$ The WaveOne Small file $(21 / 06)$ has a fixed taper of $6 \%$ over its active portion and is mainly used when the Primary WaveOne file will not progress in canals with a smooth reproducible glide path. It is mainly designed to work in smaller diameter, longer length, and more apically curved root canals. ${ }^{67}$

The rationale behind the use of a single Primary WaveOne instrument (25/08) began with the assumption of Buchanan when he defined the ideal diameter for the final instrument used for curved root canals as ISO sizes 20 or $25 .{ }^{68}$

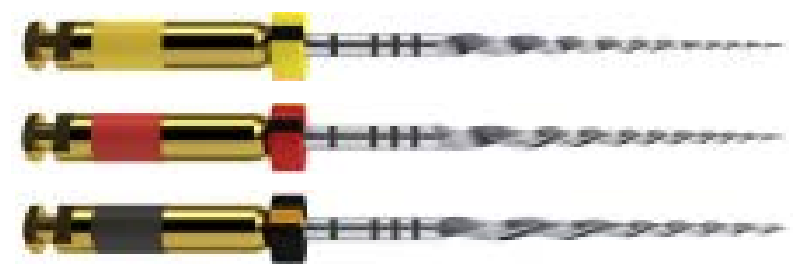

Figure 12. WaveOne system (Dentsply Sirona).

Each of the WaveOne instruments exhibits a modified convex triangular cross section at the tip end and a convex triangular cross section at the coronal end, which improves overall instrument flexibility. The convex triangular section is modified with a radial land at the tip and presents a cutting angle projected to the left that differentiates it from continuous rotation systems. ${ }^{47}$

The variable pitch flutes along the length of the instrument are said to considerably improve the safe use of these files. The WaveOne instruments are used in a modified CW/CCW movement. These instruments are used with different angles in cutting and noncutting motions in a partial reciprocation motion of $170^{\circ} / 50^{\circ}$ with an average speed of $350 \mathrm{rpm}^{39}$
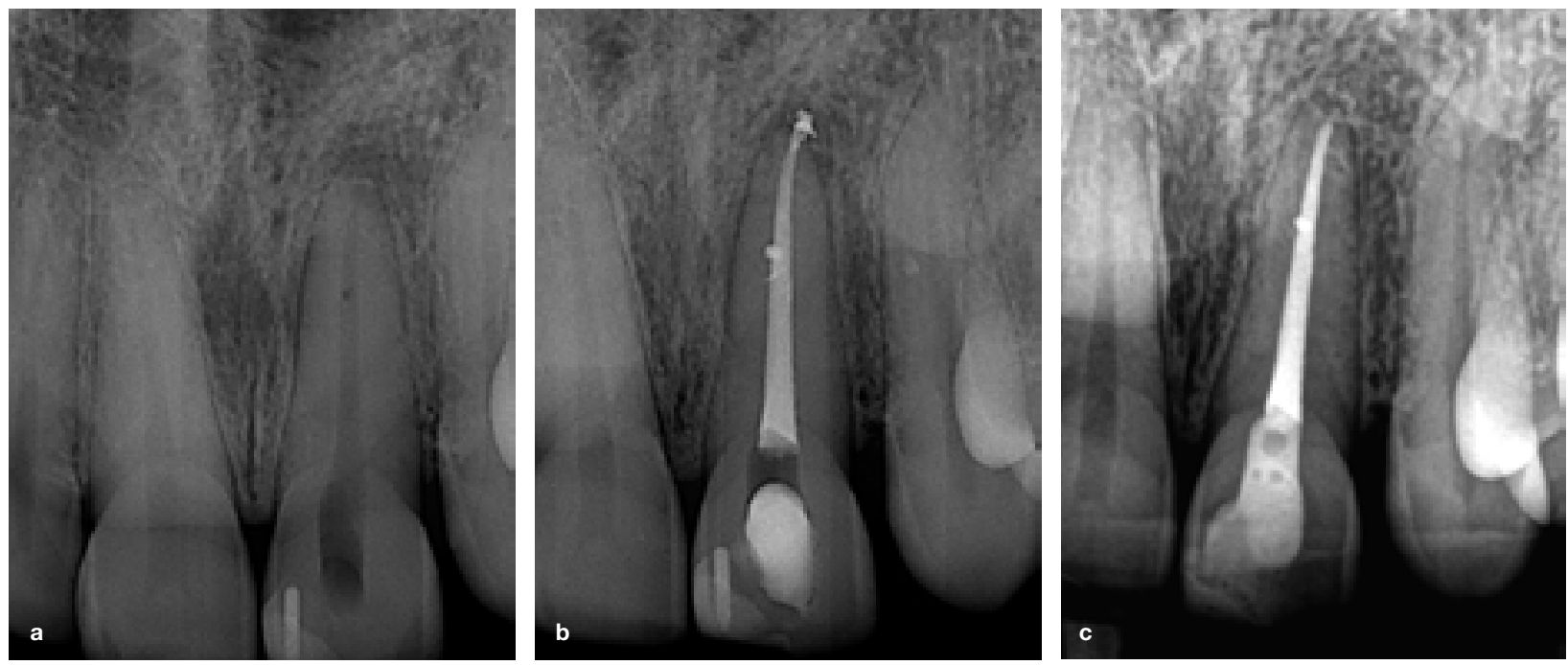

Figure 11. (a) Preoperative periapical radiograph;

(b) Immediate postoperative result after the root canal system was obturated with size 40 GuttaCore Obturator;

(c) Postoperative result at a follow up visit five years after treatment. 


\section{Case report}

The patient, a 40 year old female presented with a non-vital maxillary central incisor (Figure 13a). Root canal preparation was done with a WaveOne Large 40/08 instrument and the root canal was obturated with a size 40 GuttaCore obturator (Dentsply Sirona) (Figure 13b). Figure $13 \mathrm{c}$ illustrates the result at a five year followup visit.

\subsection{WaveOne Gold (Dentsply Sirona)}

The conventional WaveOne system was manufactured from M-Wire technology. WaveOne Gold instruments are manufactured with the use of a post-manufacturing thermal process during which a new phase-transition point between martensite and austenite is identified to produce a file with super-elastic NiTi metal properties.

This process gives the file a gold finish and improves mechanical characteristics. The properties of gold wire have been previously discussed. The WaveOne Gold Primary file is $50 \%$ more resistant to cyclic fatigue, $80 \%$ more flexible and $23 \%$ more efficient than the conventional WaveOne Primary instrument. ${ }^{69,70}$

Owing to the super-elastic properties of the new gold metal, the file may appear slightly curved when it is removed from a curved root canal because the metal demonstrates less memory compared with conventional NiTi or M-Wire (Figure 14).

The file can either be straightened out or if it is placed back into a rootcanal it will follow the natural shape of that canal. ${ }^{69}$ Another advantage of this reduced memory

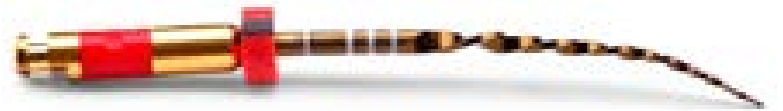

Figure 14. WaveOne Gold files may appear slightly curved when removed from a curved root canal because the metal demonstrates less memory.

of the fileis that in cases with difficult straightline access it is possible to slightly pre-curve the file to allow easy placement into the canal orifices.

Conventional WaveOne instruments are characterised by different cross-sectional designs over the entire length of the working part of the instruments. The WaveOne Gold file exhibits a unique alternating off-centered parallelogram-shaped cross-section design with two $85^{\circ}$ cutting edges (Figure 15). ${ }^{69}$

According to Ruddle, this design limits the engagement between the file and the dentine to only one or two contact points at any given cross section. ${ }^{70}$ This reduces taper-lock and the screw-effect, improves safety, increases cutting efficiency, and provides more chip space to auger debris coronally, in comparison with its predecessor WaveOne.

The newly designed files are also manufactured with an ogival (pointed arch shape), roundly tapered and semi-active guiding tip to ensure that progress along canals is safe with a secured and confirmed reproducible glide path. ${ }^{69,70}$

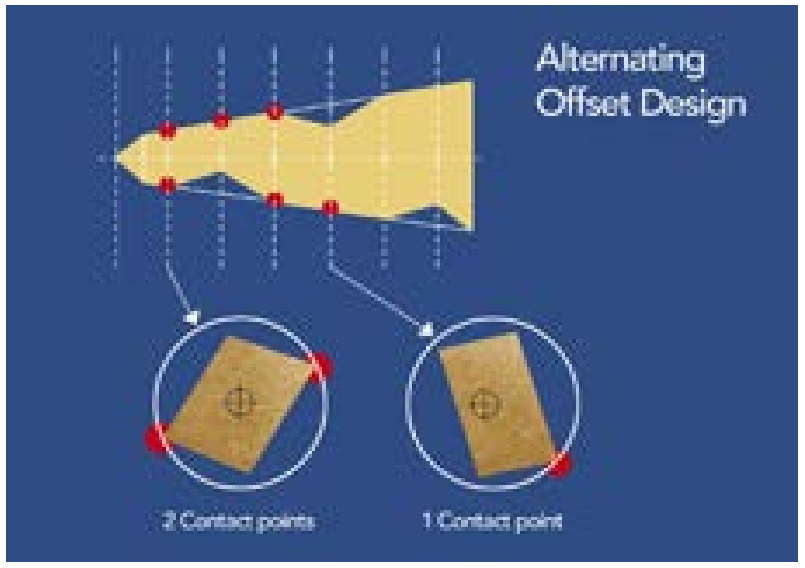

Figure 15. Schematic representation illustrating the alternating off-centered parallelogram-shaped cross-section design with two $85^{\circ}$ cutting edges. The design limits engagement between the file and dentine to only one or two points of contact at any given cross section (Adapted from Ruddle, 2016).

The WaveOne Gold single-file reciprocating system is available in four different file tip sizes in lengths of $21 \mathrm{~mm}$, $25 \mathrm{~mm}$, and $31 \mathrm{~mm}$ :

1. WaveOne Gold Small File (yellow ring) (Figure 16) with tip of the file size ISO 20 and the first $3 \mathrm{~mm}$ of the file (D1-D3) having a continuous taper of $7 \%$.

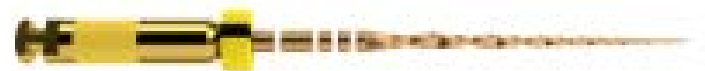

Figure 16. WaveOne Gold Small File (20/07).

2. WaveOne Gold Primary File (red ring) (Figure 17) with tip of the file size ISO 25 and the first $3 \mathrm{~mm}$ of the file (D1-D3) having a continuous taper of $7 \%$.

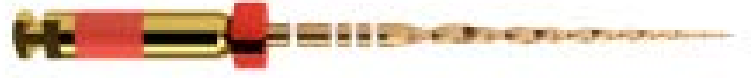

Figure 17. WaveOne Gold Primary File (25/07).

3. WaveOne Gold Medium File (green ring) (Figure 18) with tip of the file ISO 35 and the first $3 \mathrm{~mm}$ of the file (D1-D3) having a continuous taper of $6 \%$.

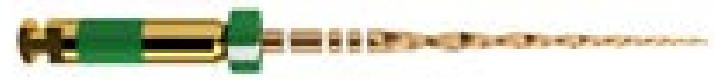

Figure 18. WaveOne Gold Medium File (35/06).

4. WaveOne Gold Large File (white ring) (Figure 19) with tip of the file ISO 45 and the first $3 \mathrm{~mm}$ of the file (D1-D3) having a continuous taper of $5 \%$.

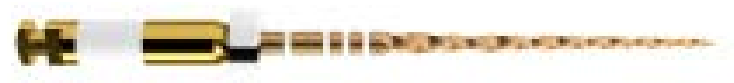

Figure 19. WaveOne Gold Large File (45/05).

From D4-D16 each file demonstrates a progressively decreasing-percentage tapered design to ensure more flexibility and to preserve more dentine in the body of the prepared root canal to ensure more conservative root canal preparations. ${ }^{69,70}$

The WaveOne GOLD files also have shortened $11 \mathrm{~mm}$ handles that improve straight-line access into the posterior region of the mouth. They are colour-coded (accor- 
ding to ISO size) with an ABS ring which expands after autoclaving to promote the philosophy of single use. ${ }^{69}$

All the above mentioned features produce a file system with improved mechanical and clinical benefits to ensure predictable root canal preparation. In the majority of cases a single file can be used to complete root canal preparation with adequate resistance form to ensure exchange of irrigation solutions for adequate disinfection prior to root canal obturation in single- or multipleroot canal systems. According to the manufacturer, the Primary 25/07 file is usually the only file needed to fully shape almost any given canal. The semi-active guiding tip of the file is said to enable its progression along canals that have undergone glide path enlargement. ${ }^{70}$

The WaveOne Gold CCW engaging angle is 150 degrees, while the CW disengaging angle is 30 degrees. Three CCW/CW cutting cycles of the file describe one full circle of rotation. According to Ruddle there are three major clinical advantages to WaveOne Gold's unique movement: (1) compared with continuous rotation, there is improved safety, as the CCW engaging angle is designed to be less than the elastic limit of each file; (2) in contrast with equal $\mathrm{CW} / \mathrm{CCW}$ angles, unequal CW/CCW angles enable a file to more readily advance toward the desired working length without the use of excessive and potentially dangerous inward pressure; (3) compared with equal $\mathrm{CW} / \mathrm{CCW}$ angles, unequal angles strategically enhance the auguring of debris out of the canal. ${ }^{70}$

\section{Case report}

The patient, a 37 year old female, presented with irreversible pulpitis on her mandibular right first molar (Figure 20a). After access cavity preparation five root canal systems were detected (mesiobuccal, mesiolingual, midmesial, distobuccal and distolingual) (Figure 20b).

Glide path preparation was done with a WaveOne Gold glider and root canal preparation was done with the Primary WaveOne Gold file (25/08). Figure 20c shows the final result after root canal obturation with WaveOne Primary Gutta Percha points and Pulp Canal Sealer, using the Calamus Dual Obturation Unit.

\subsection{Reciproc Blue (VDW)}

Over the last few years, Reciproc (VDW) (Figure 21) and WaveOne (Dentsply Sirona) have been touted as the most commercially available systems with reciprocating motion for root canal preparation. In 2011 the Reciproc System was introduced to the market by VDW (Munich, Germany) as a single-file reciprocating system. The claim was made that root canals could be completely prepared with only one Reciproc instrument.

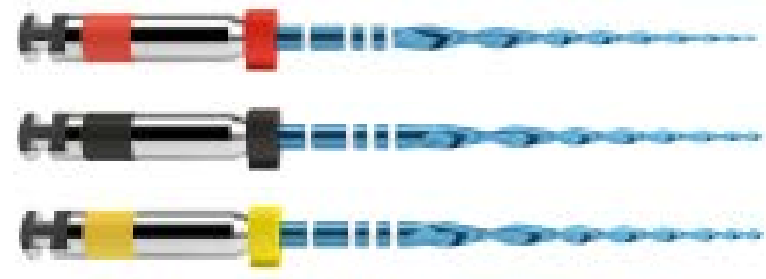

Figure 21. Reciproc Blue (VDW) - 25 (red), 40 (black) and 50 (yellow).

According to Bürklein et al. Reciproc allows for more rapid shaping than full-sequence rotary systems and is suitable for use in curved canals. Reciproc files have a tip diameter of 25 and a taper angle of $0.08 .{ }^{12}$ The tapers are fixed $3 \mathrm{~mm}$ from the apex of the files and decrease in the middle and coronal sections. ${ }^{71}$ The Reciproc file is S-shaped with two cutting edges and its manufacture requires the use of $\mathrm{M}$-Wire alloy. ${ }^{72}$

Reciproc Blue (Fig. 21), is based on its predecessor Reciproc, and was recently launched by VDW (Munich, Germany). Blue NiTi is a newly developed alloy that is obtained through a proprietary-specific oxide surface layer thermo-mechanical manufacturing process.

Like M-Wire and Gold, Blue NiTi is thermally treated $\mathrm{NiTi}$ designed to improve the mechanical properties of endodontic instruments such as fatigue resistance, flexibility, cutting efficiency, and canal centering ability. ${ }^{73,74}$
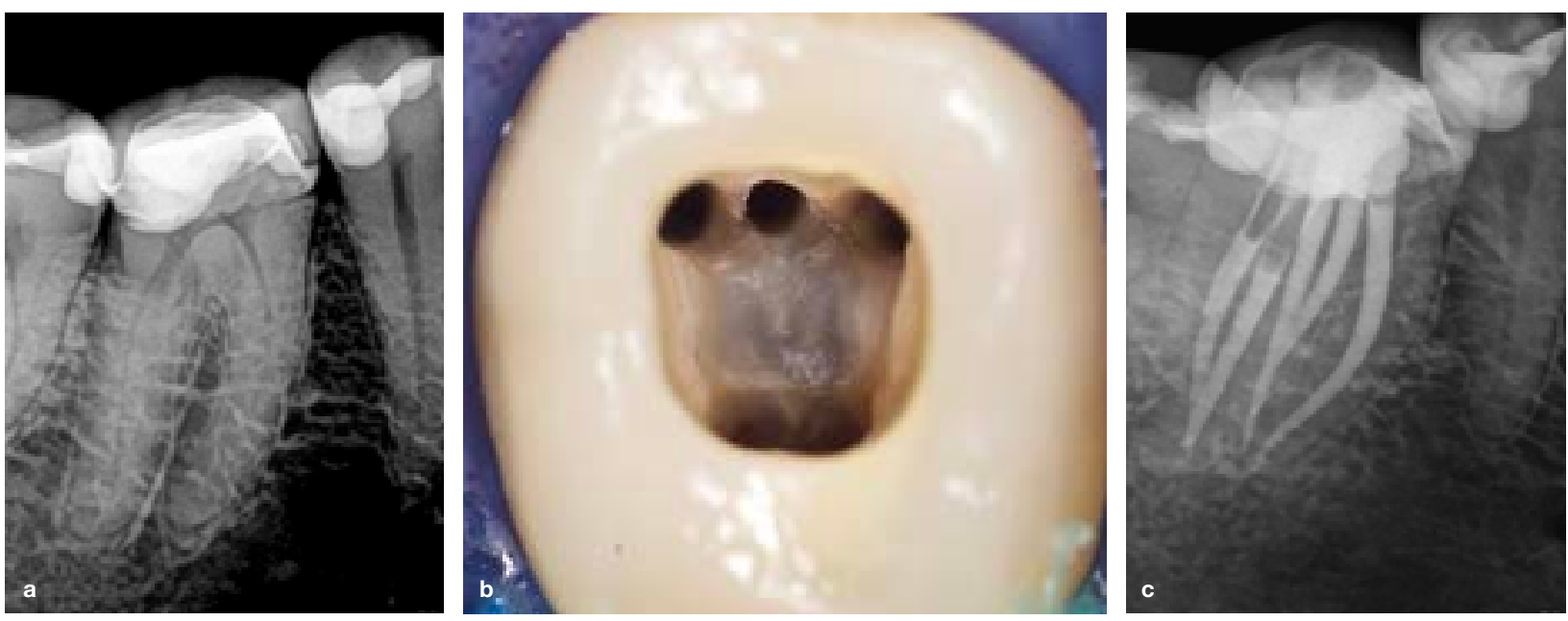

Figure 20. (a) Preoperative periapical radiograph.

(b) Magnified occlusal view of the pulp chamber.

Note the three mesial and 2 distal root canal systems.

(c) Postoperative result after obturation.

Note the three mesial root canals, with the midmesial canal joining with the mesiobuccal root canal system in the apical third. 
Thermal treatment modifications, in addition to the reciprocating motion, have already been shown to extend the life span of a NiTi instrument and its resistance to fatigue in comparison with files designed for continuous rotation movement. ${ }^{17,54}$

Blue NiTi is produced after NiTi has undergone a complex heating-cooling proprietary treatment that results in a visible layer of titanium oxide in the surface of the instrument. This treatment controls the transition temperatures and creates a shape memory alloy, which is claimed by the manufacturer to result in superior mechanical properties and performance of the NiTi instruments. ${ }^{21,25}$

Reciproc Blue is available in sizes 25 (with a taper of $8 \%$ ), 40 (with a taper of $6 \%$ ) and 50 with a taper of $5 \%$. $A$ recent study compared the bending resistance and cyclic fatigue of conventional Reciproc files with that of Reciproc Blue. ${ }^{75}$ The study concluded that the Blue thermally treated $\mathrm{NiTi}$ files showed overall improved performances when they were compared with conventional M-Wire super-elastic NiTi. Reciproc Blue demonstrated improved flexibility, enhanced fatigue resistance and reduced micro-hardness while at the same maintaining similar characteristics of the surface.

\section{Case report}

The patient, a 47 year old male, presented with a large carious lesion on his previously restored mandibular right second premolar (Figure 22a). After caries removal, working length was determined (Figure 22b) and a glide path prepared with the R-Pilot glide path instrument (VDW) and root canal preparation was done with the 25/08 Reciproc Blue instrument. Figure 22c depicts the final result after root canal obturation.

\section{Conclusion}

An increase in flexural strength, an increased resistance to cyclic fatigue as well as a decreased modulus of elasticity are some of the advantages of modern endodontic canal preparation systems. Single file rotary and reciprocating systems also ensure ease of use and reduced preparation time. Selecting the appropriate canal shaping system remains case dependant and in this paper the authors illustrated some of the advantages and clinical applications of these modern endodontic canal shaping systems.

\section{References}

1. Berutti E, Negro A, Lendini M, Pasqualini D. Influence of manual preflaring and torque on the failure rate of ProTaper rotary instruments. J Endod. 2004; 30(4):228-30.

2. Hülsmann M, Peters O, Dummer P. Mechanical preparation of root canals: shaping goals, techniques and means. Endod Top [Internet]. 2005; 10(1):30 -76. Available from: http://onlinelibrary. wiley.com/doi/10.1111/j.1601-1546.2005.00152.x/abstract.

3. Goldberg M, Dahan S, Machtou P. Centering ability and influence of experience when using WaveOne single-file technique in simulated canals. Int J Dent. 2012; 1-7. Available from: http://dx.doi.org/10.1155/2012/206321.

4. Peters O, Paqué F. Current developments in rotary root canal instrument technology and clinical use: a review. Quintessence Int (Berl). 2010; 41:479-88.

5. Peters O, De Azevedo Bahia M, Pereira E. Contemporary root canal preparation: Innovations in biomechanics. Dent Clin North Am. 2017; 6(1):37-58.

6. Lopes H, Elias C, Vieira V, Moreira E, Marques R, de Oliveira $\mathrm{J}$, et al. Effects of electropolishing surface treatment on the cyclic fatigue resistance of BioRace nickel-titanium rotary instruments. J Endod. 2010; 36:1653-7.

7. Pasqualini D, Alovisi M, Cemenasco A, Mancini L, Paolino D, Bianchi C, et al. Micro-computed tomography evaluation of ProTaper NEXT and BioRace shaping outcomes in maxillary first molar curved canals. J Endod. 2015; 41(10):1706-10. Available from: http://dx.doi.org/10.1016/j.joen.2015.07.002.

8. Capar I, Ertas H, Ok E, Arslan H, Ertas E. Comparative study of different novel nickel-titanium rotary systems for root canal preparation in severely curved root canals. J Endod. 2014; 40(6):852-6.

9. Bürklein S, Benten S, Schäfer E. Shaping ability of different single-file systems in severely curved root canals of extracted teeth. Int Endod J. 2013; 46(6):590-7.

10. Türker S, Uzunoğlu E, Aslan M. Evaluation of apically extruded bacteria associated with different nickel-titanium systems. J Endod. 2015; 41:953-5.
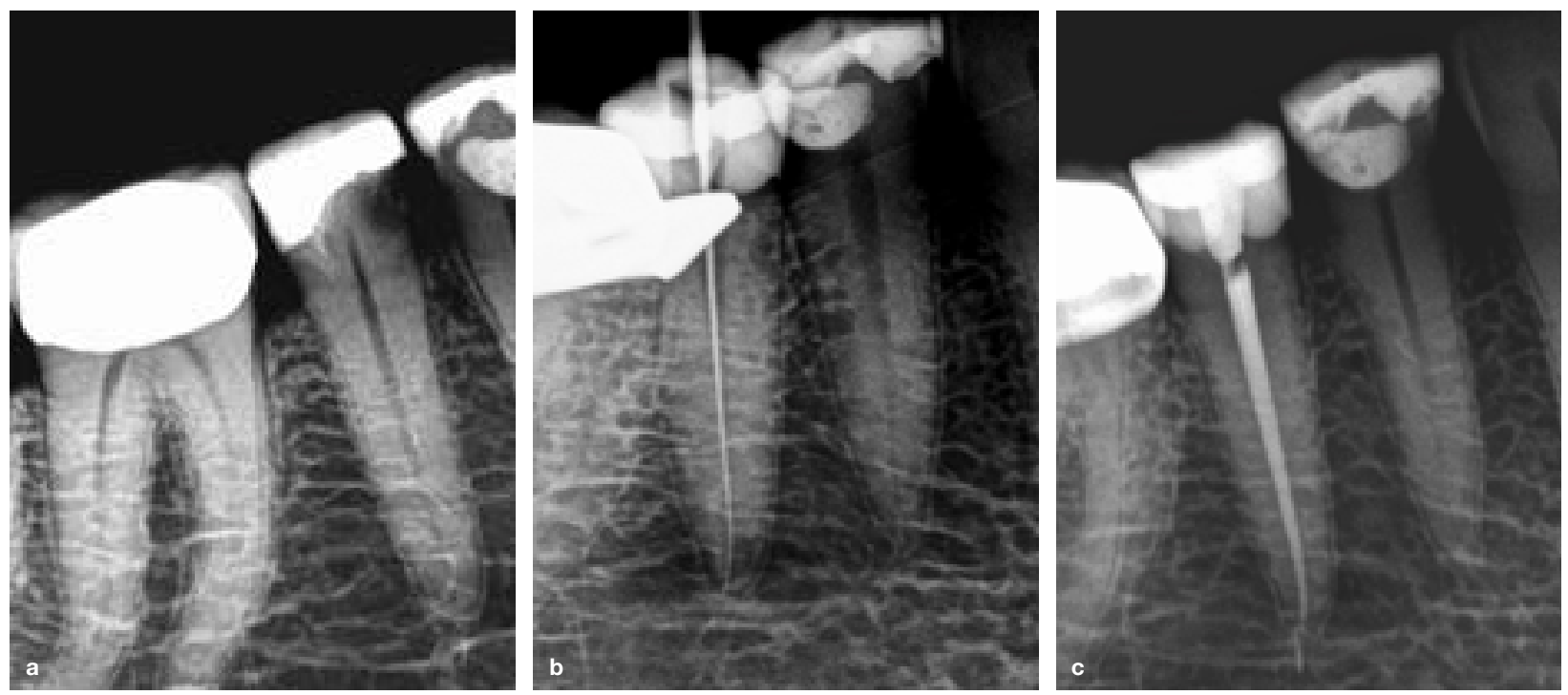

Figure 22. (a) Preoperative periapical radiograph.

(b) Periapical radiograph confirming the working length

(c) Postoperative result after root canal obturation. 
11. Bürklein S, Schäfer $E$. The influence of various automated devices on the shaping ability of Mtwo rotary nickel-titanium instruments. Int Endod J. 2006; 39:945-51.

12. Bürklein S, Hinschitza K, Dammaschke T, Schäfer E. Shaping ability and cleaning effectiveness of two single-file systems in severely curved root canals of extracted teeth: Reciproc and WaveOne versus Mtwo and ProTaper. Int Endod J. 2012; 45:449-61.

13. Saber S, Nagy M, Schäfer E. Comparative evaluation of the shaping ability of WaveOne, Reciproc and OneShape single-file systems in severely curved root canals of extracted teeth. Int Endod J. 2015; 48:109-14.

14. Pereira E, Singh R, Arias A, Peters O. In vitro assessment of torque and force generated by novel ProTaper NEXT instruments during simulated canal preparation. J Endod. 2013; 39:1615-9.

15. Varela-Patiño $P$, Ibañez-Párraga A, Rivas-Mundiña $B$, Cantatore G, Otero X, Martin-Biedma B. Alternating versus continuous rotation: a comparative study of the effect on instrument life. J Endod. 2010; 36(1):157-9.

16. Franco V, Fabiani C, Taschieri S, Malentacca A, Bortolin M, Del Fabbro M. Investigation on the shaping ability of nickeltitanium files when used with a reciprocating motion. J Endod. $2011 ; 37: 1398-401$

17. De-Deus G, Moreira E, Lopes H, Elias C. Extended cyclic fatigue life of F2 Pro-Taper instruments used in reciprocating movement. Int Endod J. 2010; 43:1063-8.

18. You S, Bae K, Baek S, et al. Lifespan of one nickel-titanium rotary file with reciprocating motion in curved root canals. J Endod. 2010; 36:1991-4.

19. You Y, Cho Y. A comparison of the shaping ability of reciprocating NiTi instruments in simulated curved canals. Restor Dent Endod. 2012; 37:220-7.

20. Marzouk A, Ghoneim A. Computed tomographic evaluation of canal shape instrumented by different kinematics rotary nickel-titanium systems. J Endod. 2013; 39:906-9.

21. Hieawy A, Haapasalo M, Zhou H, Wang Z, Shen Y. Phase transformation behaviour and resistance to bending and cyclic fatigue of ProTaper Gold and ProTaper Universal instruments. $J$ Endod. 2015; 41(7):1134-8. Available from: http://dx.doi. org/10.1016/j.joen.2015.02.030.

22. Ruddle C. The ProTaper technique. Endod Top. 2005; 19: 187-90.

23. Kaval M, Capar I. Evaluation of the cyclic fatigue and torsional resistance of novel nickel-titanium rotary files with various alloy properties. J Endod. 2017; 42(12):10-3.

24. Elnaghy A, Elsaka S. Shaping ability of ProTaper Gold and ProTaper Universal files by using cone-beam computed tomography. Indian J Dent Res. 2016; 37-42.

25. Silva E, Muniz B, Pires F, Neves A, Souza E, De-deus G. Comparison of canal transportation in simulated curved canals prepared with ProTaper Universal and ProTaper Gold systems. Restor Dent Endod. 2016; 41:1-5.

26. Scianamblo M. USPTO 6942484, 7094056,7955078 and 20060228669. Attorney: Fish \& Richardson P.C Current U.S Classification: 433/102, International Classification A61C005/ 02, 2011.

27. Gagliardi J, Versiani M, De Sousa-Neto M, Plazas-Garzon A, Basrani B. Evaluation of the shaping characteristics of Pro Taper Gold, ProTaper NEXT, and ProTaper Universal in curved canals. J Endod. 2015; 41(10):1718-24.

28. Van Der Vyver P, Scianamblo M. Clinical guidelines for the use of ProTaper NEXTinstruments (Part I). Dent Trib. 2014; 7:12-6.

29. Da-Silva Limoeiro A, Dos Santos A, De Martin A, Kato A, Fontana C, Gavini G, et al. Micro-computed tomographic evaluation of two nickel-titanium instrument systems in shaping root canals. J Endod. 2016; 42(3):496-9. Available from: http:// linkinghub.elsevier.com/retrieve/pii/S0099239915011371.
30. Busquim S, Cunha R, Freire L, Gavini G, Machado M, Santos M. A micro-computed tomography evaluation of longoval canal preparation using reciprocating or rotary systems. Int Endod J. 2015; 48:1001-6.

31. De-Deus G, Belladonna F, Souza E, Silva E, Neves A, Alves H, et al. Micro-computed tomographic assessment on the effect of ProTaper NEXT and Twisted file adaptive systems on dentinal cracks. J Endod. 2015; 41(7):1116-9. Available from: http://linkinghub.elsevier.com/retrieve/pii/S0099239915 001399.

32. Ammon D, Shotton V, Gao Y, Maxwell R. Endodontic instruments and methods of manufacturing thereof. US 8916009; 8916009, 2014.

33. Elnaghy A, Elsaka S. Laboratory comparison of the mechanical properties of TRUShape with several nickel-titanium rotary instruments. Int Endod J. 2017; 50:805-812.

34. Dentsply Tulsa Dental Specialties. TRUShape 3D Confirming Files Brochure. 2015.

35. Bortoluzzi E, Carlon DJ, Meghil M, El-Awady A, Niu L, Bergeron $B$, et al. Efficacy of $3 D$ conforming nickel titanium rotary instruments in eliminating canal wall bacteria from oval-shaped root canals. J Dent. 2015; 43:597-604.

36. Webber J, Machtou P, Pertot W, Kuttler S, West J. The WaveOneTM single-file reciprocating system. Roots. 2011; (1):1-9.

37. Parashos $\mathrm{P}$, Messer $\mathrm{H}$. Rotary NiTi instrument fracture and its consequences. J Endod. 2006; 32:1031-43.

38. Walia $\mathrm{H}$, Brantley W, Gerstein $\mathrm{H}$. An initial investigation of the bending and torsional properties of Nitinol root canal files. J Endod. 1988; 14:346-51.

39. Grande N, Mohamed H, Ahmed A, Cohen S. Current assessment of reciprocation in endodontic preparation: A compre hensive review - Part I: Historic perspectives and current applications. J Endod. 2015; 41(11):1778-83.

40. Lindeburg M. Civil Engineering Reference Manual for the PE Exam. $7^{\text {th }}$ ed. Belmont, CA: Professional Publications; 1999.

41. Pedullà E, Lo Savio F, Boninelli S, Plotino G, Grande N, Rapisarda $E$, et al. Influence of cyclic torsional preloading on cyclic fatigue resistance of nickel-titanium instruments. Int Endod J. 2015; 48:1043-50.

42. Berutti E, Chiandussi G, Paolino D, Scotti N, Cantatore G, Castellucci A, et al. Canal shaping with WaveOne Primary reciprocating files and ProTaper system: a comparative study. J Endod. 2012; 38:505-9.

43. Robinson J, Lumley P, Cooper P, Grover L, Walmsley A. Reciprocating root canal technique induces greater debris accumulation than a continuous rotary technique as assessed by 3-dimensional micro-computed tomography. J Endod. 2013; 39:1067-70.

44. De-Deus G, Arruda T, Souza E, Neves A, Magalhães K, Thuanne E, et al. The ability of the Reciproc R25 instrument to reach the full root canal working length without a glide path. Int Endod J. 2013; 46:993-8.

45. Sanches Cunha R, Junaid A, Ensinas P, Nudera W, da Silveira Bueno $E$. Assessment of the separation incidence of reciprocating WaveOne files: a prospective clinical study. J Endod. 2014; 40:922-4

46. Plotino G, Grande N, Porciani P. Deformation and fracture incidence of Reciproc instruments: a clinical evaluation. Int Endod J. 2015; 48:199-205.

47. Do-Amaral R, Leonardi D, Gabardo M, Coelho B, de Oliveira K, Filho F. Influence of cervical and apical enlargement associated with the WaveOne system on the transportation and centralization of endodontic preparations. J Endod. 2016; 1-6.

48. Varela-Patiño P, Martín-Biedma B, Rodriguez-Nogueira J, Cantatore G, Malentaca A, Ruiz-Pinón M. Fracture rate of nickel-titanium instruments using continuous versus alternating rotation. Endod Prac. 2008; 3:193-7. 
49. Generali L, Righi E, Todesca M, Consolo U. Canal shaping with WaveOne reciprocating files: influence of operator experience on instrument breakage and canal preparation time. Odontology. 2014; 102:217-22.

50. Saleh A, Tavanafar S, Vakili-Gilani P, Al Sammerraie N, Rashid F. Influence of operator's experience level on lifespan of the WaveOne Primary file in extracted teeth. Restor Dent Endod. 2013; 38(4):222-6. Available from: http://www. pubmedcentral.nih.gov/articlerender.fcgi?artid $=3843033$ \&tool=pmcentrez\&rendertype=abstract.

51. Türker S, Saglam B, Kocak M, Kocak S. The effect of glide path on the surface quality of new and used rotary and reciprocating single files: OneShape versus WaveOne. Scanning. 2014; 36:608-13.

52. Wan J, Rasimick B, Musikant B, Deutsch A. A comparison of cyclic fatigue resistance in reciprocating and rotary nickeltitanium instruments. Aust Endod J. 2011; 31:122-7.

53. Vadhana S, SaravanaKarthikeyan B, Nandini S, Velmurugan N. Cyclic fatigue resistance of RaCe and Mtwo rotary files in continuous rotation and reciprocating motion. J Endod. 2014; 40:995-9.

54. Pedullà E, Grande N, Plotino G, Gambarini G, Rapisarda E. Influence of continuous or reciprocating motion on cyclic fatigue resistance of four different nickel-titanium rotary instruments. J Endod. 2013; 39:258-61.

55. Pérez-Higueras J, Arias A, de la Macorra J. Cyclic fatigue resistance of $\mathrm{K} 3, \mathrm{~K} 3 \mathrm{XF}$, and twisted file nickel-titanium files under continuous rotation or reciprocating motion. J Endod. 2013; 39:1585-8.

56. Saber Sel D, Abu El Sadat S. Effect of altering the reciprocation range on the fatigue life and the shaping ability of WaveOne nickel-titanium instruments. J Endod. 2013; 39:685-8.

57. Gambarini G, Giansiracusa Rubini A, Al Sudani D, Gergi R, Culla $A$, De Angelis $F$, et al. Influence of different angles of reciprocation on the cyclic fatigue of nickel-titanium endodontic instruments. J Endod. 2012; 38:1408-11.

58. Shin C, Huang Y, Chi C, Lin C. Fatigue life enhancement of NiTi rotary endodontic instruments by progressive reciprocating operation. Int Endod J. 2014; 47:882-8.

59. Gambarini G, Giansiracusa Rubini A, Sannino G, Di Giorgio G, Piasecki L, Al-Sudani D, et al. Cutting efficiency of nickel titanium rotary and reciprocating instruments after prolonged use. Odontology. 2016; 104:77-81.

60. Giansiracusa Rubini A, Plotino G, Al-Sudani D, Grande N, Ermanno Putorti D, Sonnino G, et al. A new device to test cutting efficiency of mechanical endodontic instruments. Med Sci Monit. 2014; 20:374-8

61. Plotino G, Giansiracusa Rubini A, Grande N, Testarelli L, Gambarini G. Cutting efficiency of Reciproc and WaveOne reciprocating instruments. J Endod. 2014; 40:1228-30.

62. Tocci L, Plotino G, Al-Sudani D, Giansiracusa Rubini A, Sannino G, Piasecki $L$, et al. Cutting efficiency of instruments with different movements: a comparative study. J Oral Maxillofac Res. 2015; 6(1):6.

63. Dincer A, Er O, Canakci B. Evaluation of apically extruded debris during root canal retreatment with several NiTi systems. Int Endod J. 2015; 48:1194-8.

64. Silva E, Sá L, Belladonna F, Neves A, Accorsi-Mendonça T, Vieira $V$, et al. Reciprocating versus rotary systems for root filling removal: assessment of the apically extruded material. J Endod. 2014; 40:2077-80.

65. Plotino G, Mohamed H, Ahmed A, Grande N, Cohen S. Current assessment of reciprocation in endodontic preparation: A comprehensive review Part II: properties and effectiveness. J Endod. 2015; 41(12):1939-50.

66. Alattar S, Nehme W, Diemer F. The influence of brushing motion on the cutting behaviour of three reciprocating files in oval-shaped canals. J Endod [Internet]. 2015; 41(5):703-9. Available from: http://dx.doi.org/10.1016/j.joen.2014.12.016.

67. Ruddle C. Endodontic canal preparation: WaveOne single-file technique. Dent Today. 2012; 124-9.
68. Buchanan L. The standardized-taper root canal preparationPart 1. Concepts for variably tapered shaping instruments. Int Endod J. 2000; 33:516-29.

69. Webber J. Shaping canals with confidence: WaveOne GOLD single-file. Roots. 2015; 1:34-40.

70. Ruddle C. Single-file shaping technique: achieving a gold medal result. Dent Today. 2016; (January):1-7.

71. Plotino G, Grande N, Testarelli L, Gambarini G. Cyclic fatigue of Reciproc and WaveOne reciprocating instruments. Int Endod J. 2012; 45:614-8.

72. Elnaghy A, Elsaka S. Torsion and bending properties of OneShape and WaveOne instruments. J Endod. 2015; 41: 544-7.

73. Pereira E, Gomes R, Leroy A, Singh R, Peters O, Bahia M, et al. Mechanical behaviour of M-Wire and conventional NiTi wire used to manufacture rotary endodontic instruments. Dent Mater. 2103; 29(12):318-24.

74. Lopes H, Gambarra-Soares T, Elias C, Siqueira J, Inojosa I, Lopes W, et al. Comparison of the mechanical properties of rotary instruments made of conventional nickel-titanium wire, M-Wire, or nickel-titanium alloy in R-phase. J Endod. 2013; 39(4): 516-20.

75. De-Deus G, Silva E, Vieira V, Belladonna F, Elias C, Plotino $\mathrm{G}$, et al. Blue thermomechanical treatment optimizes fatigue resistance and flexibility of the Reciproc files. J Endod [Internet]. 2017; 1-5. Available from: http://linkinghub.elsevier. com/retrieve/pii/S0099239916308020. 